\title{
Pyrolytic Synthesis of Spherical Carbon Nanoshells
}

\author{
Naing Min Tun and E. G. Rakov \\ Mendeleev University of Chemical Technology of Russia, 125047 Moscow, Russian Federation,
}

Correspondence should be addressed to: Naing Min Tun; nainglay20@gmail.com

Received date: 28 May 2014; Accepted date: 2 June 2014; Published date: 8 September 2014

Academic Editor: Josef Pola

Copyright (C) 2014. Naing Min Tun and E.G.Rakov. Distributed under Creative Commons CC-BY 3.0

\begin{abstract}
The methane pyrolysis on spherical $\mathrm{SiO}_{2}$ nanoparticles with mean diameter of $40-80 \mathrm{~nm}$ has been studied at temperatures $550-800{ }^{\circ} \mathrm{C}$, methane flow rate $50-660 \mathrm{~mL} / \mathrm{min}$, and process duration 20-60 min. It is shown that this process results in the formation of core/shell composites with shells having thickness of $\sim 1-12 \mathrm{~nm}$ which are permeable to liquids. The dissolution of a core leads to the extraction of hollow carbon nanospheres.
\end{abstract}

Keywords: Carbon spherical nanoshells, methane, pyrolysis, template growth

\section{Introduction}

Carbon nanostructured materials have attracted the great interest due to their potential in a variety of applications in different areas of techniques, biology and medicine, such as adsorption, capacitive deionization, catalysis, electrocatalysis, photocatalysis, energy storage, sensory and biosensory systems, drug delivery, etc. A special type of carbon material are the hollow micro- and nanoparticles (shells, boxes, spheres) having low density, high values of conductivity and specific surface. The better way to form such three-dimensional (3D) nanostructures is synthesis over specific nanoparticles, viz., template growth. Metals, crystalline and amorphous oxides, carbides, silicides, and fluorides can be used as a template material.
Various templating techniques have been developed to synthesize carbon core-shell micro- and nanoparticles, such as vacuum sputtering (Hayashi, 1996), molecular beam epitaxy (Jerng, 2011 a; Jerng, 2011 b), sol-gel method (Zhu, 2009), hydrothermal approach (Xuan, 2007; Liu, 2012; Li, 2013), electrostatic interaction (Yang, 2010; Chen, 2012 a), aerosol spraying (Wen, 2013) and catalytic chemical vapor deposition (CVD).

Among the several approaches reported to-date, CVD of carbon on substrates has a great interest due to the low-cost production of graphene layers, simplicity and easy scaling-up.

The carbon shells usually represents the irregular graphene layers which can be thin (one to three layers) (Rümmeli, 2007; Wang, 2012), have up to 8-10 layers (Rümmeli, 2008; Teunissen, 2001; Rümmeli, 2010 a), or be 
rather thick. The number of carbon layers can be tuned by changing the growth time and the temperature.

Certain transfer-free methodologies for flat substrates have been also proposed (Ismach, 2010; Yan, 2011; Wang, 2013). Direct growth of graphene ribbons on sapphire and $\mathrm{SiO}_{2}$ dielectric substrates using chemical vapor deposition has been studied by Ismach et al. (2010) and Wang et al. (2013). The process includes deposition of $\mathrm{Cu}$ or Ni films, chemical vapor deposition using hydrocarbons and metal etching. Graphene ribbons up to few millimeters long were formed along the periphery of pre-patterned $\mathrm{Ni}$ films (Wang, 2013).

Many oxides can encourage the carbon graphitization. Different hydrocarbons were used for the pyrolysis and covering the oxide surface. An impressive series of works on developing, testing and use of 3D composite materials has been done in Japan by M. Inagaki et al. $(1998,2004,2006)$.

As a rule, the materials were produced by metal-catalyst-free pyrolysis of poly(vinyl chloride), poly(ethylene terephtalate), hydroxyethylcellulose or poly(vinyl alcohol) in contact with ceramic particles at temperatures between 700 and $1000{ }^{\circ} \mathrm{C}$ in inert atmosphere. At a definite thickness of carbon shells the values of their specific surface and porosity can be significantly increased.

Application of the CVD route in which the nanoparticles of $\mathrm{Al}_{2} \mathrm{O}_{3}, \mathrm{TiO}_{2}$ and $\mathrm{MgO}$ are exposed to ethanol vapor was recently explored by Bachmatiuk et al. (2013). Pyrolysis of cyclohexane vapor over $\mathrm{MgO}$ was also studied by Rümmeli (2010 a). The growth of graphene shells on $\mathrm{MgO}$ and $\mathrm{ZrO}_{2}$ particles by pyrolysis of $\mathrm{C}_{2} \mathrm{H}_{2}$ at low temperatures was studied by Rümmeli et al. (2010 b; 2010 a) and Scott (2011).

Porous hollow carbon@sulfur composites were formed earlier using silica particles $200 \mathrm{~nm}$ in diameter (Jayaprakash, 2011), $500 \mathrm{~nm}$ in diameter (Shin, 2013) and $150-200 \mathrm{~nm}(\mathrm{He}$, 2014) as template. Spherical $\mathrm{SiO}_{2}$ matrix with diameter more than $100 \mathrm{~nm}$ were used for the carbon shells by pyrolysis of different organic compounds, but not methane (Yoon, 2002; Kim, 2003; Su, 2006; Kim, 2009; Chen 2012, b; Bottger-Hiller, 2013; Qiao, 2013).

The synthesis of carbon/MgO core/shell and pure carbon shell particles at $\mathrm{CH}_{4}$ decomposition using $\mathrm{MgO}$ as a template was described by Davydov et al. (2012).

Here we report on the formation of hollow carbon nanoshells by pyrolysis of methane on spherical $\mathrm{SiO}_{2}$ nanoparticles.

\section{Experimental Part}

\section{Sample Preparation}

Nanoparticles of $\mathrm{SiO}_{2}$ produced by plasma pyrolysis of $\mathrm{SiF}_{4}$ have been used as a matrix. The size distribution of $\mathrm{SiO}_{2}$ particles is shown in Fig. 1. It is seen that the most part of them has diameter $30-90 \mathrm{~nm}$ with average value of $50-70 \mathrm{~nm}$. 


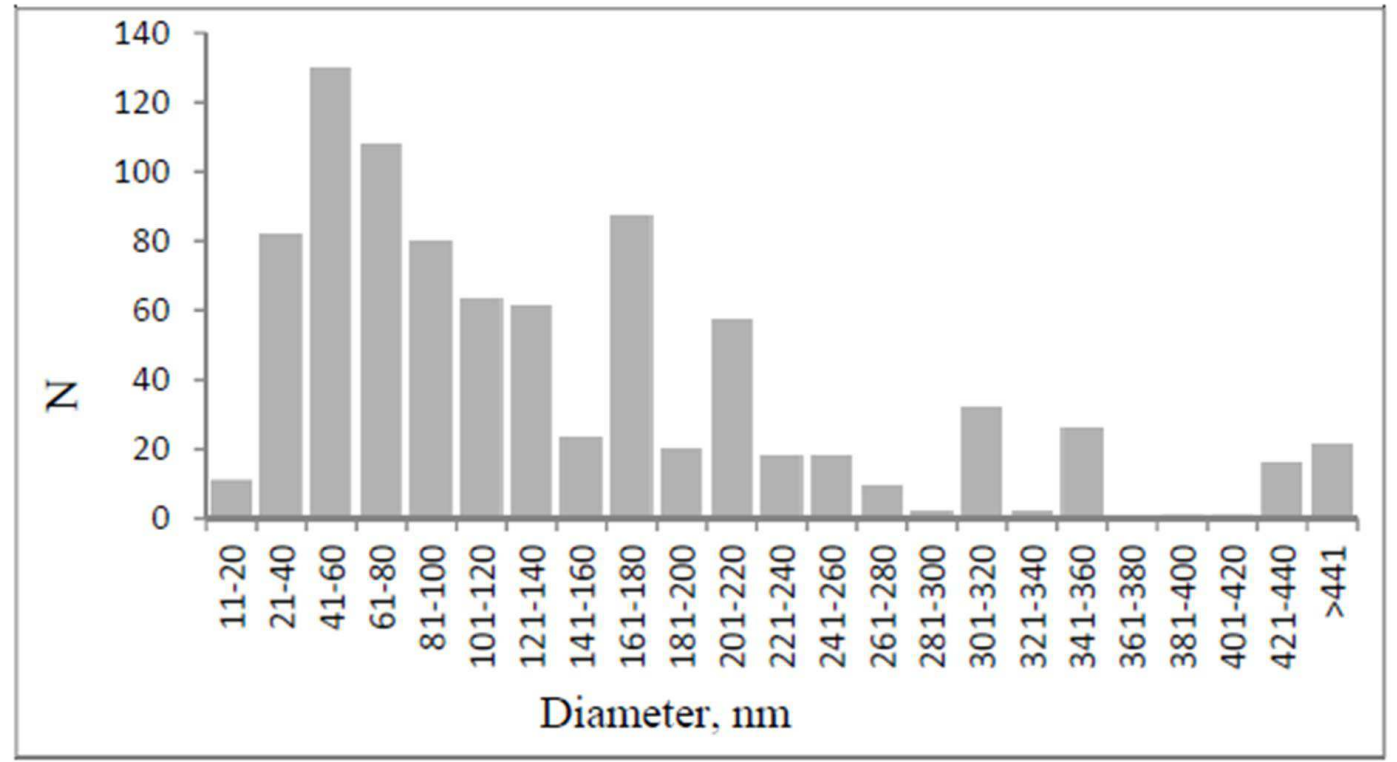

Fig. 1. Distribution of silica particles by size.

Domestic gas with $99 \%$ of methane content is used without any cleaning for the experiments. 3D

carbon networks are prepared on $\mathrm{SiO}_{2}$ by CVD at ambient pressure.

The carbon-encapsulated $\mathrm{SiO}_{2}$ nanoparticles are synthesized in a horizontal tube furnace (Fig.
2). The reactor consists of a sectioned quartz tube $55 \mathrm{~mm}$ in outer diameter. The tube has working area heated by electric furnace, and cold area, with a sealing leg between the areas. We introduce methane into quartz tube $1 \mathrm{~h}$ before the pyrolysis to achieve the full displacement of air

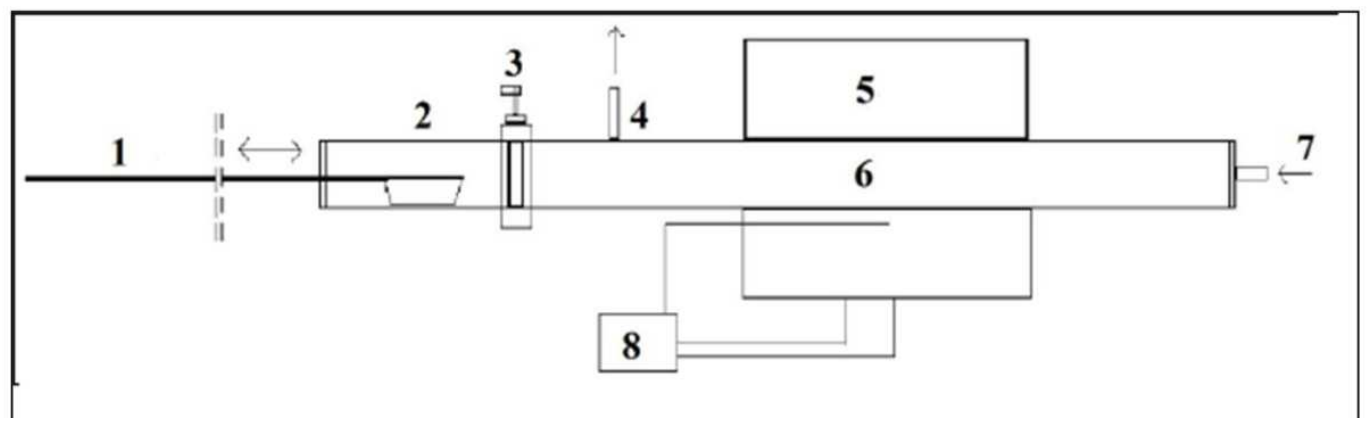

Fig. 2. Reactor for pyrolysis: 1 - metal stick for introducing of the boat to hot area; 2 - boat with $\mathrm{SiO}_{2}$ nanoparticles in cold area; 3 - sealing leg; 4 - tube for exhausted gases; 5 - electric heating furnace; 6 - quartz tube; 7 - tube for gas input; 8 - equipment for measuring and adjustment of temperature. 
from the reactor. The boat with $250 \mathrm{mg}$ of $\mathrm{SiO}_{2}$ was put into reactor by means of a special stick after heating the working area. The boat is held for a definite time in the hot area, then moved to the cold area, cooled and drawn out. The product is weighted and analyzed. Gas flow $(100-800 \mathrm{~mL} / \mathrm{min})$ is preliminary calibrated at room temperature. The flow rate is controlled precisely by volume flow controller.

\section{Product Characterization}

For the determination of deposited carbon mass, the samples were calcined at $750-800{ }^{\circ} \mathrm{C}$ during $3 \mathrm{~h}$ in air, cooled in closed exiccator and weighted. The thickness of carbon shells is estimated using total mass gain of deposited carbon and the mean size of the encapsulated $\mathrm{SiO}_{2}$ particles.

Scanning electron microscopy (Chem JEOL, JSM-6510LV) and transmission electron microscopy (FEI Tecnai $\mathrm{G}^{2} 30 \mathrm{ST}$ ) were used to study the morphology of the starting $\mathrm{SiO}_{2}$ particles, encapsulated nanoparticles and hollow shells. The specific surface of start materials and the products is measured by BET method (Sorbi MS).

\section{Results and discussion}

The $\mathrm{CH}_{4}$ pyrolysis is observed at the temperature $500-900{ }^{\circ} \mathrm{C}$. The typical dependencies of mass change on the process duration and gas flow rate at relatively high temperatures are represented by the curves with saturation (Fig. 3 and 4).

By analogy with the results of hydrocarbon pyrolysis over $\mathrm{Cu}, \mathrm{Ni}$ and other metals, one can suppose that the surface of oxides exerts a catalytic influence on pyrolysis reaction. With increasing deposit thickness and process duration this influence weakens and finally ceases. Ceramic materials also has been used as catalysts of methane decomposition, e. g. by Hussain and Iqbal (2011). The activity of $\mathrm{SiO}_{2}$ was found to be much lower than $\mathrm{MgO} / \mathrm{SiO}_{2}$ or $\mathrm{Ni}$ doped $\mathrm{MgO} / \mathrm{SiO}_{2}$.

It would be noted that at the highest temperatures, along with the carbon deposition on the tested samples, it takes place on the walls of quartz reactor. This uncontrolled deposition follows by the increasing of hydrogen content in reaction gases and some distortion of calculated data. The increasing of $\mathrm{H}_{2}$ concentration in reaction gases delays the pyrolysis reaction too.

The final mass gain due to formation of carbon deposit on $\mathrm{SiO}_{2}$ depends on the temperature (Fig. 5), and at $850-900^{\circ} \mathrm{C}$ rises up to 72 mass $\%$.

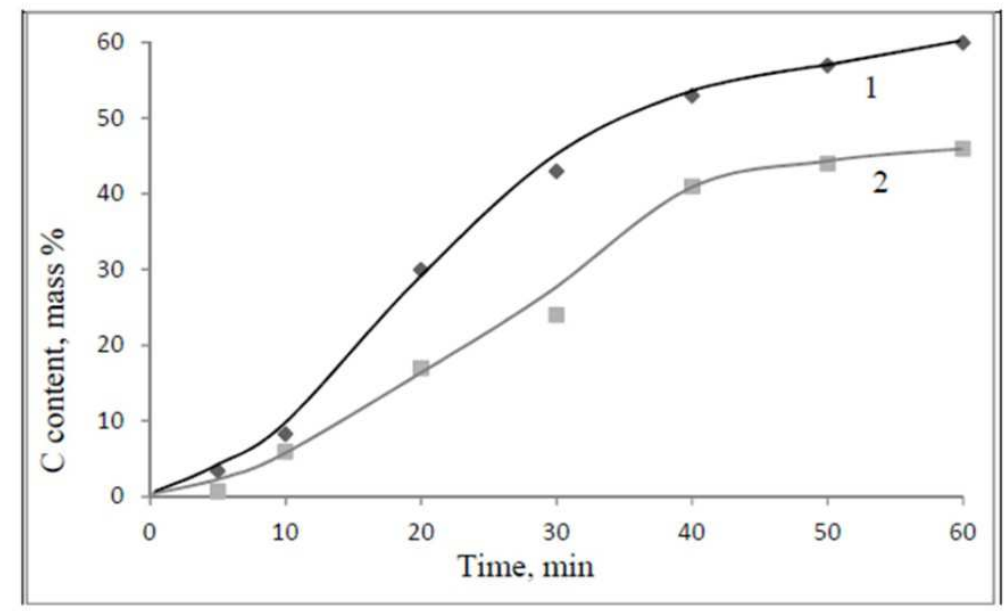

Fig. 3. The influence of pyrolysis time on mass of carbon deposit on $\mathrm{SiO}_{2}$ at $\mathrm{CH}_{4}$ flow rate of 330 $\mathrm{mL} / \mathrm{min}$ and temperature of $800{ }^{\circ} \mathrm{C}(1)$ and $700{ }^{\circ} \mathrm{C}(2)$. 


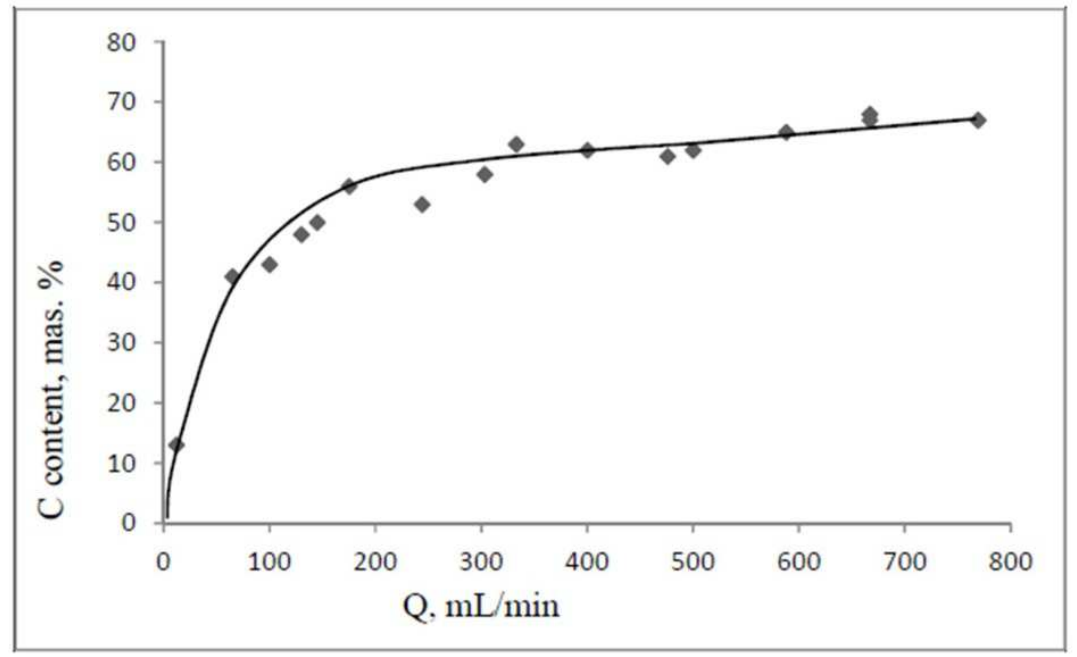

Fig. 4. The influence of $\mathrm{CH}_{4}$ flow rate on mass of carbon deposit on $\mathrm{SiO}_{2}$ at temperature of $850 \mathrm{o}$ $C$ and process duration of 60 min.

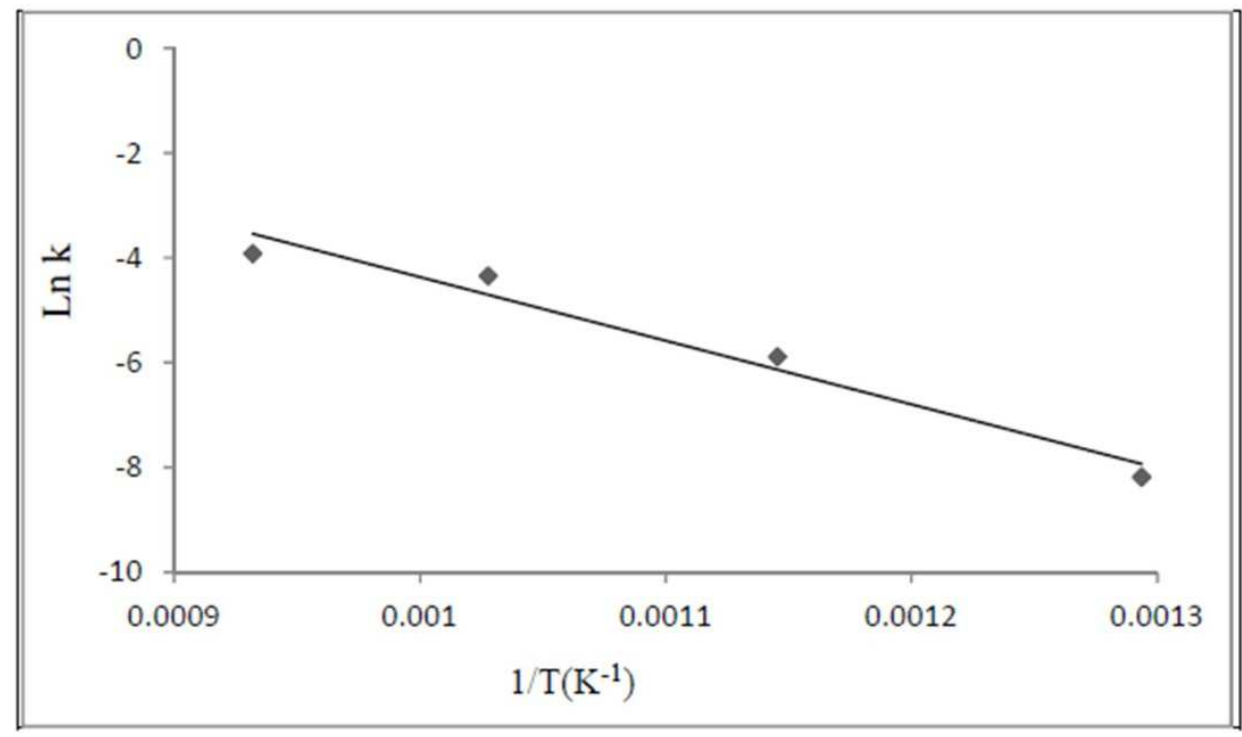

Fig. 5. The Arrhenius plot of carbon deposition on $\mathrm{SiO}_{2}$ matrix.

The value of apparent activation energy that is estimated using medium part of the curve, is near $100 \mathrm{~kJ} / \mathrm{mole}$. This value is appreciably lower than the activation energy determined by Hussain and Iqbal (2011), which is equal to 186 $\mathrm{kJ} /$ mole, and defined in the work of Brüggert et al. (1999) - $446 \mathrm{~kJ} / \mathrm{mole}$. The difference may be related to the lower temperatures in our experiments and to the lower activity of $\mathrm{SiO}_{2}$ catalyst. Also, it is likely that our data are influenced by carbon deposition process on the walls of quartz tube.
The results of electron microscopy analysis are evident of thin carbon layer formation on $\mathrm{SiO}_{2}$ particles. As it is seen in Fig. $6 \mathrm{~b}-\mathrm{e}$, the shells covered whole surface of particles. The diameters of produced hollow carbon spheres closely repeats the size of initial $\mathrm{SiO}_{2}$ particles.

Some of the empty shells are slightly distorted. To calculate medium diameter of $\mathrm{SiO}_{2}$ particles, we takes into account overall numbers of particles in definite fractions of $20 \mathrm{~nm}$ in size at the interval of 21-210 $\mathrm{nm}$. Assuming the mean 
diameter of particles equal to $60 \mathrm{~nm}$ and considering mass gain during deposition of carbon shells, it is possible to calculate the conventional thickness of the shells. The calculated thickness values are shown in Table 1.

Table 1. The calculated thickness of the shells at different experimental Conditions

\begin{tabular}{|l|l|l|llll|}
\hline $\begin{array}{l}\text { Tempera- } \\
\text { ture, }{ }^{\circ} \mathrm{C}\end{array}$ & $\begin{array}{l}\text { Duration, } \\
\text { min }\end{array}$ & Carbon content, & \multicolumn{4}{|l|}{ Shell thickness, } \\
mass \% & & \multicolumn{3}{l|}{ at SiO } & diameter, nm \\
\hline 550 & 60 & 5.0 & 0.5 & 0.6 & 0.7 & 0.8 \\
600 & $30^{*}$ & $7.5^{*}$ & 0.6 & 0.9 & 1.0 & 1.2 \\
600 & 60 & 10 & 0.8 & 1.2 & 1.4 & 1.6 \\
650 & 60 & 34 & 3.0 & 3.6 & 4.2 & 4.8 \\
700 & 60 & 47 & 3.5 & 4.2 & 4.9 & 5.6 \\
750 & 60 & 65 & 5.5 & 6.6 & 7.7 & 8.8 \\
800 & 60 & 72 & 5.6 & 6.7 & 7.8 & 8.9 \\
\hline
\end{tabular}

* Gas flow rate $466 \mathrm{~mL} / \mathrm{min}$, in other cases $330 \mathrm{~mL} / \mathrm{min}$.

As it is seen, the value of the shell thickness can be controlled by alteration of pyrolysis temperature and duration.

$\mathrm{SiO}_{2}$ matrixes covered by carbon shells can be easily dissolved in $\mathrm{HF}$ aqueous solution, thus the shells are microporous and permeable to solutions. Therefore, the calculated values are approximate and underestimated by $15-20 \%$. The real thickness of shells produced at $600{ }^{\circ} \mathrm{C}$ and pyrolysis duration of $30 \mathrm{~min}$, measured in micrographs (Fig. 6), is 1$12 \mathrm{~nm}$. This interval coincides with calculated values. At lower temperature and process duration, the thickness less than $1 \mathrm{~nm}$ can be achieved.
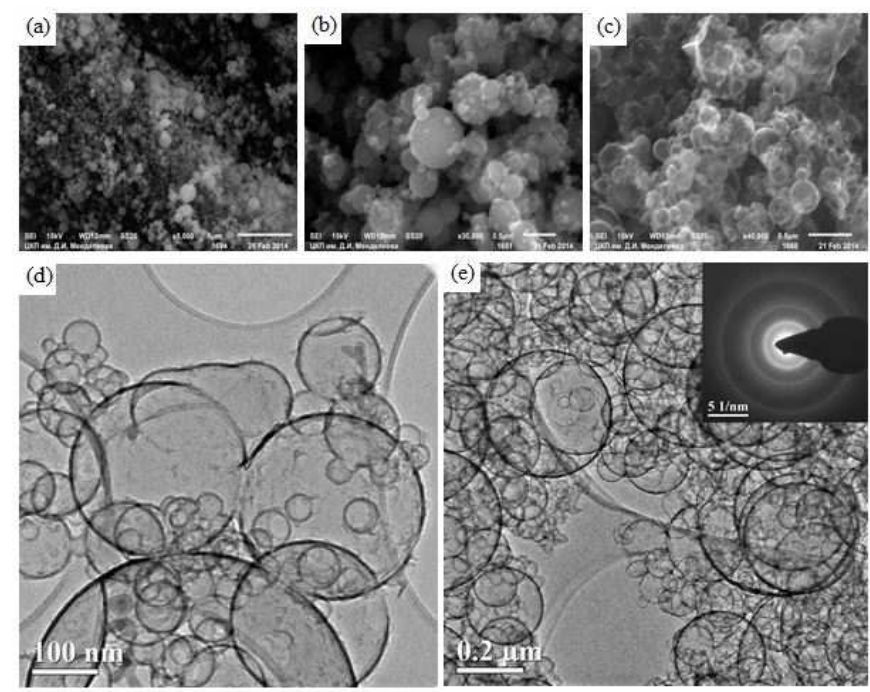

Fig. 6. Carbon shells produced by $\mathrm{CH}_{4}$ pyrolysis over spherical $\mathrm{SiO}_{2}$ particles (SEM): a - silica particles (SEM); b - silica particles with carbon shells (SEM); c - carbon shells (SEM); d carbon shells (TEM); e - carbon shells (TEM) and their diffraction pattern. 
The carbon spherical shells with the thickness of some nanometers become not strong and do not keep their habitus. Therefore destroyed spheres are seen on some of the pictures (Fig 6 d), but its number is negligible. Coalescent particles are also observed.

In 1959 Cullis et al (1959) has showed that carbon deposited from methane on silica substrate had a normal graphite structure, in other words represented graphene (which was not yet discovered).

The electron diffraction pattern (Fig 6 e) corresponds to the polycrystalline graphite structure of carbon deposit.

The lower is the pyrolysis temperature, the higher are porosity and specific surface values of shells. The specific surface of shells synthesized at $600{ }^{\circ} \mathrm{C}$ was $175 \mathrm{~m}^{2} / \mathrm{g}$, whereas specific surface value of a matrix $\mathrm{SiO}_{2}$ particles was equal to $12-13 \mathrm{~m}^{2} / \mathrm{g}$.

Carbon shells having thickness lower than 5-7 $\mathrm{nm}$ in the case of individual particles must be transparent or semitransparent, as it was shown earlier by Kaplas and Svirko (2012). Our shells are transparent in electron beam, however as a whole they retain black color.

The unique spherical carbon shells synthesized here have high electrical conductivity and can be used as electrode material for capacitive deionization (electrosorption) of waste water effluents.

\section{Conclusion}

A simple method for the preparation of 3D architectures is developed via a pyrolytic process. The methane pyrolysis at temperatures of $500-900{ }^{\circ} \mathrm{C}$ on the spherical nanoparticles of $\mathrm{SiO}_{2}$ allows to get a core-shell hybrid composites, and the consequent dissolution of $\mathrm{SiO}_{2}$ matrix leads to formation of isolated hollow carbon shells. The main part of these shells have diameters of $40-80 \mathrm{~nm}$ with a shell thickness of 1-12 $\mathrm{nm}$. The values of shell density and specific surface are temperature dependent: The lowering of synthesis temperature leads to the reduction of density and to the increasing of specific surface.

\section{Acknowledgement}

The authors thank Dr. E. Melnichenko for the granting of $\mathrm{SiO}_{2}$ samples; $\mathrm{V}$. Zhigalina for TEM investigation; Mendeleev Research Center for SEM investigation; O. Vinokurova for the measurement of specific surface.

\section{Conflict of interests}

The authors have declared that no conflict of interest exists.

\section{References}

1.Bachmatiuk, A., Mendes, R. G., Hirsch, C., Jähne, C., Lohe, M. R., Grothe, J., Kaskel, S, Fu, L., Klingerer, R., Eckert, J., Wick, P., and Rümmeli, M. H. (2013) 'Few-Layer Graphene Shells and Nonmagnetic Encapsulates: A Versatile and Nontoxic Carbon Nanomaterial,' ACS Nano, 7 (12) 10552-10562.

2. Böttger-Hiller, F., Kempe, P., Cox, G., Panchenko, A., Janssen, N., Petzold, A., ThurnAlbrecht, T., Borchardt, L., Rose, M., Kaskel, S., Georgi, C., Lang, H., and Spange, S. (2013), 'Twin Polymerization at Spherical Hard Templates: An Approach to Size-Ajustable Carbon Hollow Spheres with Micro- and Mesoporous Shells,' Angewandte Chemie International Edition, 52 (23) 6088-6091.

3. Brüggert, M., Hu, Z., and Hüttinger, K. J. (1999) 'Chemistry and kinetics of chemical vapor deposition of pyrocarbon. VI. Influence of temperature using methane as a carbon source,' Carbon, 37 (12), 2021-2030.

4. Chen, D., Ji, G., Ma, Y., Lee J. Y., and Lu J. (2012 a) 'Graphene-Encapsulated Hollow $\mathrm{Fe}_{3} \mathrm{O}_{4}$ Nanoparticle Aggregates as a HighPerformance Anode Material for Lithium-Ion Batteries,' Applied Materials \& Interfaces, 3 (8), 3078-3083 .

5. Chen, X., Kierzek, K., Cendrowski, K., Pelech, I., Zhao, X., Feng, J., Kalenczuk, R. J., Tang, T., and Mijowska, E. (2012 b) 'CVD generated mesoporous hollow carbon spheres as supercapacitors,' Colloids and Surfaces A: Physicochemical and Engineering Aspects, 396, 246-250. 
6. Cullis C.F., Manton J.E., Thomas G.B., and Wilman H. (1959) 'The Structure and Crystal Growth of Carbon Deposits Formed by Pyrolysis of Some Hydrocarbons and Chlorohydrocarbons,' Acta Crystallographica, 12 (5), 382-384.

7. Davydov, S. Yu., Kryukov, A. Yu., Gerya V. O., Izvol'skii I. M., and Rakov, E. G. (2012) 'Preparation of a Platelike Carbon Nanomaterials Using $\mathrm{MgO}$ as a Template,' Russian Journal of Physical Chemistry, 48 (3) 244-248.

8. Hayashi, T., Hirono, S., Tomita, M., and Unemura, S. (1996) 'Magnetic thin films of cobalt nanocrystals encapsulated in graphitelike carbon,' Nature, 381 (6585) 772-774.

9. He, G., Evers, S., Liang, X., Cuisiner, M., Garsuch, A., and Nazar, L. F. (2014) 'Tailoring Porosity in Carbon Nanospheres for LithiumSulfur Battery Cathodes,' ACS Nano, 7 (12), 10920-10930.

10.Hussain S.T., Iqbal M. (2011) 'Pyrolysis of methane by catalytic properties exhibited by ceramics,' Journal of Analytical and Applied Pyrorysis, 90 (2) 106-111.

11.Inagaki, M., Miura, H., and Konno, H. (1998) 'A new simple process for carbon coating of ceramic particles using poly(vinyl chloride),' Journal of European Ceramic Society, 18 (8) 1011-1015.

12.Inagaki, M., Kobayashi, S., Kojin, F., Tanaka, N., Morishita, T., and Tryba, B. (2004) 'Pore structure of carbon coated on ceramic particles,' Carbon, 42 (15) 3153-3158.

13.Inagaki, M., Morishita, T., Toyoda, M., Tsumura, T., and Konno, H. (2006) 'Carbon Coatings of Ceramics,' Tanso, 2006 (224) 308-317.

14.Ismach, A., Druzgalski, C., Penwell, S., Schwartzberg, A., Zheng, M., Javey, A., Bokor, J., and Zhang, Y. (2010) 'Direct chemical vapor deposition of graphene on dielectric surfaces,' Nano Letters, 10 (5) 1542-1548.

15. Jayaprakash, N., Shen, J., Moganty, S. S., Corona, A., and Archer, L. A. (2011) 'Porous Hollow Carbon@Sulfur Composites for Higy-
Power Lithium-Sulfur Batteries,' Angewandte Chemie International Edition, 50 (26), 5904-5908.

16.Jerng, S. K., Yu, D. S., Kim, Y. C., Ryou, J., Hong, S., Kim, C., Yoon, S., Efetov, D. K., Kim, P., and Chun, S. H. (2011, a) 'Nanocrystalline graphite grown on sapphire by carbon molecular beam epitaxy,' Journal of Physical Chemistry C, 115 (11) 4491-4494.

17.Jerng, S. K., Yu, D. S., Lee, J. H., Kim, C., Yoon, S., and Chun, S.-H. (2011, b) 'Graphitic carbon growth on crystalline and amorphous oxide substrates using molecular beam epitaxy,' Nanoscale Research Letters, 6 (1) 565-574.

18.Kaplas, T. and Svirko, Yu. (2012) 'Direct deposition of semitransparent conducting pyrolytic carbon films,' Journal of Nanophotonics, 6 (1) 061703.

19.Kim, M., Yoon, S. B., Sohn, K., Kim, J. Y., Shin, C.-H., Hyeon, T., and Yu, J.-S. (2003) 'Synthesis and characterization of spherical carbon and polymer capsules with hollow macroporous core and mesoporous shell structures,' Microporous and Mesoporous Materials, 63 (1-3) 1-9.

20.Kim, J. H., Fang, B., Yoon, S. B., and Yu, J.-S. (2009) 'Hollow core/mesoporous shell carbon capsule as an unique cathode catalyst support in direct methanol fuel cell,' Applied Catalysis B: Environmental, 88 (3-4) 368-375.

21.Li, L., Seng, K., Chen, Z., Liu, H., Nevirkovets, I. P., and Guo, Z. (2013) 'Synthesis of $\mathrm{Mn}_{3} \mathrm{O}_{4}$ encapsulated graphene sheet nanocomposites via a facile, fast microwave hydrothermal method and their supercapacitive behavior,' Electrochimica Acta, 87 801-808.

22.Liu, J., Zhu, Y., Liang, J., and Qian, Y. (2012) 'Synthesis of $\mathrm{In}_{3} \mathrm{O}_{3} /$ Carbon Core-Shell Nanospheres and their Electrochemical Performance,' International Journal of Electrochemical Science, 7 (2012) 55745580.

23.Qiao, Z. A., Guo, B., Binder, A. J., Chen, J., Veith, G. M., and Dai S. (2013) 'Controlled 
synthesis of mesoporous carbon nanostructures via a "silica-assisted" strategy,' Nano Letters, 13 (1) 207-212.

24.Rümmeli, M. H., Kramberger, C., Grüneis, A., Ayala, P., Gemming, T., Büchner, B., and Pichler, T. (2007) 'On the Graphitization Nature of Oxides for the Formation of Carbon Nanostructures,' Chemistry of Materials , 19 (17) 4105-4107.

25.Rümmeli, M. H., Schäffel, F., de los Arcos, T., Haberer, D., Bachmatiuk, A., Kramberger, C., Ayala, P., Borowiak-Palen, E., Adebimpe, D., Gemming, T., Leonhardt, A., Rellinghaus, B., Schulz, L., Pichler, T., and Büchner, B. (2008) 'On the graphitization role of oxide support in carbon nanotube CVD synthesis,' Physica Status Solidi B, 245 (10) 1939-1942.

26.Rümmeli, M. H., Bachmatiuk, A., Scott, A., Börrnert, F., Warner, J. H., Hoffmann, V., Lin, J. H., Cuniberti, G., and Büchner B. (2010 a) 'Direct Low-Temperature Nano-Graphene Synthesis over a Dielectric Insulator,' $A C S$ Nano, 4 (7) 4206-4210.

27.Rümmeli, M. H., Shäffel, F., Bachmatiuk, A., Adebimpe, D., Trotter, G., Börrnert, F., Scott, A., Coric, E., Sparing, M., Rellinghaus, B., McCormic, P. G., Cuniberti, G., Knupfer, M., Schultz, L., and Büchner, B. (2010 b) 'Investigating the Outskirts of $\mathrm{Fe}$ and $\mathrm{Co}$ Catalyst Particles in Alumina-Supported Catalytic CVD Carbon Nanotube Growth,' ACS Nano, 4 (2) 1146-1152.

28.Scott, A., Dianat, A., Börrnert, F., Bachmatiuk, A., Zhang, S., Warner, J. H., Borowiak-Paleń, E., Knupfer, M., Büchner B., Cuniberti, G., and Rümmeli, M. H. (2011) 'The catalytic potential of high- $k$ dielectrics for graphene formation,' Applied Physics Letters, 98 (7) 073110.

29.Shin, E. S., Kim, M. S., Cho, W. I., and Oh, S. H. (2013) 'Sulfur/graphitic hollow carbon sphere nanocomposite as a cathode material for high-power lithium-sulfur battery,' Nanoscale Research Letters, 8 (1) 343-354.

30.Su, F., Zhao, X. S., Wang, Y., Wang, L., and Lee J. Y. (2006) 'Hollow carbon spheres with a controllable shell structure,' Journal of Materials Chemistry, 16 (45) 4413-4419.
31.Teunissen, W., de Groot, F. M. F., Geus, J., Stephan, O., Tence, M., and Colliex, C., (2001) 'The Structure of Carbon Encapsulated NiFe Nanoparticles,' Journal of Catalysis, 204 (1) 169-174.

32.Wang, S., Huang, X., He, Y., Huang, H., Wu, Y., Hou, L., Liu, X., Yang, T., Zou, J., and Huang, B. (2012) 'Synthesis, growth mechanism and thermal stability of copper nanoparticles encapsulated by multi-layer graphene,' Carbon, 50 (6) 2119-2125.

33.Wang, D., Tian, H., Yang, Y., Xie, D., Ren, T.-L., and Zhang, Y. (2013) 'Scalable and Direct Growth of Graphene Micro Ribbons on Dielectric Substrates,' Scientific Reports, 3, 1348. DOI: 10.1038/srep01348.

34.Wen, Y., Zhu, Y., Langrock, A., Manivannan, A., Ehrman, S. H., and Wang, C. (2013) 'Graphene-Bonded and Encapsulated Si Nanoparticles for Lithium Ion Battery Anodes,' Small, 9 (16) 2810-2816.

35.Xuan, S., Hao, L., Jiang, W., Gong, X., Hu, Y., and Chen, C. (2007) 'A facile method to fabricate carbon-encapsulated $\mathrm{Fe}_{3} \mathrm{O}_{4}$ core/shell composites,' Nanotechnology, 18 (3) 035602.

36.Yan, Z., Peng, Z., Sun, Z., Yao, J., Zhu, Y., Liu, Z., Ajayan, P. M., and Tour, J. M. (2011) 'Growth of bilayer graphene on insulating substrates,' ACS Nano, 5 (10) 8187-8192.

37.Yang, S., Feng, X., Ivanovichi, S., and Müllen, K. (2010) 'Fabrication of GrapheneEncapsulated Oxide Nanoparticles: Towards High-Performance Anode Materials for Lithium Storage,' Angewandte Chemie International Edition, 49 (45), 8408-8411.

38.Yoon, S. B., Sohn, K., Kim J. Y., Shin, C.-H., Yu, J.-S., and Hyeon, T. (2002) 'Fabrication of Carbon Capsules with Hollow Macroporous Core/Mesoporous Shell Structures,' Advanced Materials, 14 (1) 19-21.

39.Zhu, S., Zhang, D., Chen, Z., and Zhang, Y. (2009) 'Controlled synthesis of core/shell magnetic iron oxide/carbon systems via a self-templated method,' Journal of Materials Chemistry, 19 (41) 7710-7715. 